\title{
Allopatric differentiation in the acoustic communication of a weakly electric fish from southern Africa, Marcusenius macrolepidotus (Mormyridae, Teleostei)
}

\author{
Michael Lamml • Bernd Kramer
}

Received: 22 August 2005 /Revised: 27 July 2006 / Accepted: 3 August 2006 / Published online: 11 November 2006

(C) Springer-Verlag 2006

\begin{abstract}
A few species of the weakly electric snoutfish, the African freshwater family Mormyridae, have been reported to vocalise. However, allopatric populations of a single species were never compared. Members of three allopatric Marcusenius macrolepidotus populations, originating from the Upper Zambezi River in Namibia, the Buzi River (Mozambique), and the Incomati River system in South Africa, vocalised with pulsatile growl- and tonal hoot sounds in dyadic confrontation experiments. A high rate of growling accompanied territorial and agonistic interactions and also non-threatening interactions between males and females, which in one pair appeared to be courtship. Growl sound characteristics of $M$. macrolepidotus from the Incomati system differed from those of the Upper Zambezi in a significantly higher frequency of the first harmonic (mean, $355 \mathrm{~Hz}$ vs $266 \mathrm{~Hz}$ ). The two vocalising males from the Buzi River generated growls about twice as long as the other fish. Furthermore, the growl pulse period was about $4 \mathrm{~ms}$ in M. macrolepidotus from the Upper Zambezi River and from the Incomati system, but $6 \mathrm{~ms}$ in M. macrolepidotus from the Buzi River. Hoots were only observed in agonistic encounters. Hoot oscillograms showed a sinusoidal waveform, and the mean duration of this sound was similar in Incomati system fish (mean, $161 \mathrm{~ms}$ ), Upper Zambezi fish (172 ms) and Buzi fish (103 and $145 \mathrm{~ms}$ for
\end{abstract}

Communicated by T. Czeschlik

M. Lamml • B. Kramer $(\bowtie)$

Zoologisches Institut der Universität Regensburg, 93040 Regensburg, Germany

e-mail: bernd.kramer@biologie.uni-regensburg.de the two vocalising individuals). The mean frequency of the first hoot harmonic was higher in Incomati system fish $(326 \mathrm{~Hz})$ than in Upper Zambezi fish $(245 \mathrm{~Hz})$. Both growl and hoot occurred only in the presence of conspecifics, probably signalling the presence and condition of an opponent, territory owner or potential mate. This is the first evidence for (1) sound production and acoustical communication in another species and genus, M. macrolepidotus, from southern Africa to be (2) geographically differentiated.

Keywords Acoustic communication - Aggression ·

Electric fish $\cdot$ Territoriality $\cdot$ Vocalisation

$\begin{array}{ll}\text { Abbreviations } \\ \text { AD } & \text { antiparallel display } \\ \text { App } & \text { approach } \\ \text { B/B } & \text { bite/butt } \\ \text { Circ } & \text { circling } \\ \text { CV }_{\mathrm{b}} & \text { between-individual coefficient of variability } \\ \mathrm{CV}_{\mathrm{w}} & \text { within-individual coefficient of variability } \\ \text { EOD } & \text { electric organ discharge } \\ \text { FA } & \text { frontal attack } \\ \text { FD } & \text { frontal display } \\ \text { FFT } & \text { fast Fourier transformation } \\ \text { Fo } & \text { following } \\ \text { H1 } & \text { first harmonic } \\ \text { NTO } & \text { next to one another } \\ \text { PD } & \text { parallel display } \\ \text { PP } & \text { pulse period } \\ \text { SL } & \text { standard length } \\ \text { SPL } & \text { sound pressure level }\end{array}$




\section{Introduction}

A number of teleost fishes benefit from the acoustic modality whilst receiving or broadcasting information (Myrberg 1981, 1997). Sounds to attract mates are documented for many fish species, e.g. Pomacentrus partitus (Myrberg et al. 1986), Porichthys notatus (reviewed by Bass 1990), or Opsanus tau (e.g. Gray and Winn 1961). Vocalisations may also function as threat signals whilst defending a territory or nest site (e.g. Ladich 1990, 1997, 1998; Ladich et al. 1992). Speciesspecific vocalisations occur in various families such as Cichlidae (Lobel 1998; Amorim et al. 2004), Mormyridae (Crawford et al. 1997b), and Pomacentridae (Myrberg et al. 1978, Spanier 1979), and a signal function of vocalisations has been demonstrated in some of these (reviewed by Myrberg 1997; Zelick et al. 1999; Bass and McKibben 2003).

The predominantly nocturnal members of the Mormyridae are well-known for their electric sense, which is used in electrolocation (e.g. von der Emde and Schwarz 2002) and intra- or inter-specific communication (reviewed by Kramer 1990, 1996; Moller 1995; Hopkins 1999; Scheffel and Kramer 2006). Members of the genus Marcusenius have been the subject of several studies on electric communication in a variety of behavioural contexts (Moller 1976; Graff 1989; Scheffel and Kramer 1997; Werneyer and Kramer 2002, 2005; Hanika and Kramer 2005).

In addition to electric signalling that is restricted to close range (Moller et al. 1989), certain mormyrid species communicate with sound. Territorial, reproductively active males of the vicariant West African sibling species Pollimyrus adspersus (Crawford et al. 1986; Bratton and Kramer 1989) and Pollimyrus isidori (Crawford et al. 1997a; Crawford 1997), as well as Pollimyrus marianne males from the Upper Zambezi system (Lamml and Kramer 2005), generate complex songs, apparently to attract females to their nest site (advertisement calls). Speciesspecific vocalisations in the genus Pollimyrus are presumed to play an important role during mate choice (Crawford et al. 1997b). This hypothesis is supported by recent findings on P. marianne that differ from both West African species in the typical sequence of sound patterns and characteristics (Lamml and Kramer 2005). In addition to the genus Pollimyrus, truly distinctive acoustic displays have only been found in Petrocephalus ballayi in the form of tonal hoots (Crawford 1997), exempting the 'clicking sounds' observed in Gnathonemus petersii (Rigley and Marshall 1973).

Recent taxonomic studies on Marcusenius macrolepidotus from southern Africa indicate a complex of several allopatric populations that are well-differentiated in genetic and morphological characteristics, as well as waveforms of their electric organ discharge (Kramer et al. 1998, Kramer et al., in preparation). The authors recognise at least three, rather than a single, M. macrolepidotus population for southern Africa. One population, the present subspecies $M$. macrolepidotus angolensis (Boulenger 1905), occurs in the Upper Zambezi River, whilst the nominal species Gnathonemus pongolensis Fowler 1934, which was made synonymous with M. macrolepidotus (Peters 1852), occurs as far south as $28^{\circ}$ South in South African rivers draining into the Indian Ocean. A third population, representing topotypical M. macrolepidotus (Peters 1852), is found in the Lower Zambezi and the Buzi River system. These populations are separated by watersheds, the Indian Ocean, or the Victoria Falls.

Up to now, nothing is known about sound production in the genus Marcusenius, although Stipetic (1939) had already described gas-filled accessory structures of the inner ear for Gnathonemus macrolepidotus Peters (integrated into the genus Marcusenius by Taverne 1971). These structures were later called ear bladders (e.g. Crawford 1997) and are now known to enhance hearing in the genera Brienomyrus (Yan and Curtsinger 2000) and Pollimyrus (Fletcher and Crawford 2001; Marvit and Crawford 2000a,b).

Allopatric variation of fish vocalisations has been studied only within a few marine or estuarine species such as the toadfish O. tau (Fine 1978a,b), the damselfish Dascyllus albisella (Mann and Lobel 1998), and the anemone fish Amphiprion akallopisos (Parmentier et al. 2005). The question has not been addressed in riverine fishes with their totally different environmental constraints for dispersal and phylogeography. By experimentally pairing rivals or potential mates, we evoked vocalisations displayed during specific behaviours by members of all three allopatric $M$. macrolepidotus populations. We were particularly interested in the question of whether group differences emerged in acoustical characteristics that would strengthen the hypothesis of allopatric differentiation.

\section{Materials and methods}

Animal origin and care

We used individuals of three allopatric M. macrolepidotus populations from (1) the Upper Zambezi River (Namibia), (2) the Incomati (South Africa), and (3) the Buzi River system (Mozambique; Fig. 1).

Twenty-one individuals (11 males, 10 females) from an Upper Zambezi population were caught on 21 August 1999 near Kalimbeza/Lisikili, east of Katima Mulilo, Caprivi Strip, Namibia (17³2'27.3"S, 2431'26.2'E; coll.: F.H. van der Bank and B. Kramer; Fig. 2), and transported to our 
laboratory in Regensburg, Germany by an overnight flight. The South-African M. macrolepidotus ( $n=11$, see below) originated from two locations of the Incomati River system that are about $67 \mathrm{~km}$ apart: Sabie River (caught 29-30 March 1996 near Lower Sabie tourist camp, Kruger

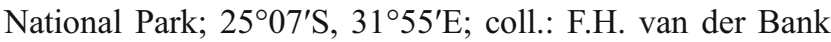
and B. Kramer) and the Crocodile River (caught 14 February 1997 near the town of Kaapmuiden, Mpumalanga Province, $25^{\circ} 30^{\prime} 35^{\prime \prime} \mathrm{S}, 31^{\circ} 11^{\prime} 58^{\prime \prime} \mathrm{E}$; coll.: F.H. van der Bank and J. Engelbrecht). Together with seven offspring from Crocodile River individuals reared in Germany (Werneyer and Kramer 2005), we observed seven males and four females [standard length (SL), 9.3-21 cm]. Two males and two females from the middle Buzi River system (SL, 8.8$13 \mathrm{~cm}$ ), caught on 29 September 2002 near Dombe,

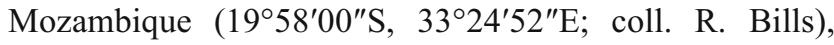
represented topotypical $M$. macrolepidotus. The Buzi River system is connected with the Lower Zambezi River, the type locality for M. macrolepidotus (Peters 1852). Males

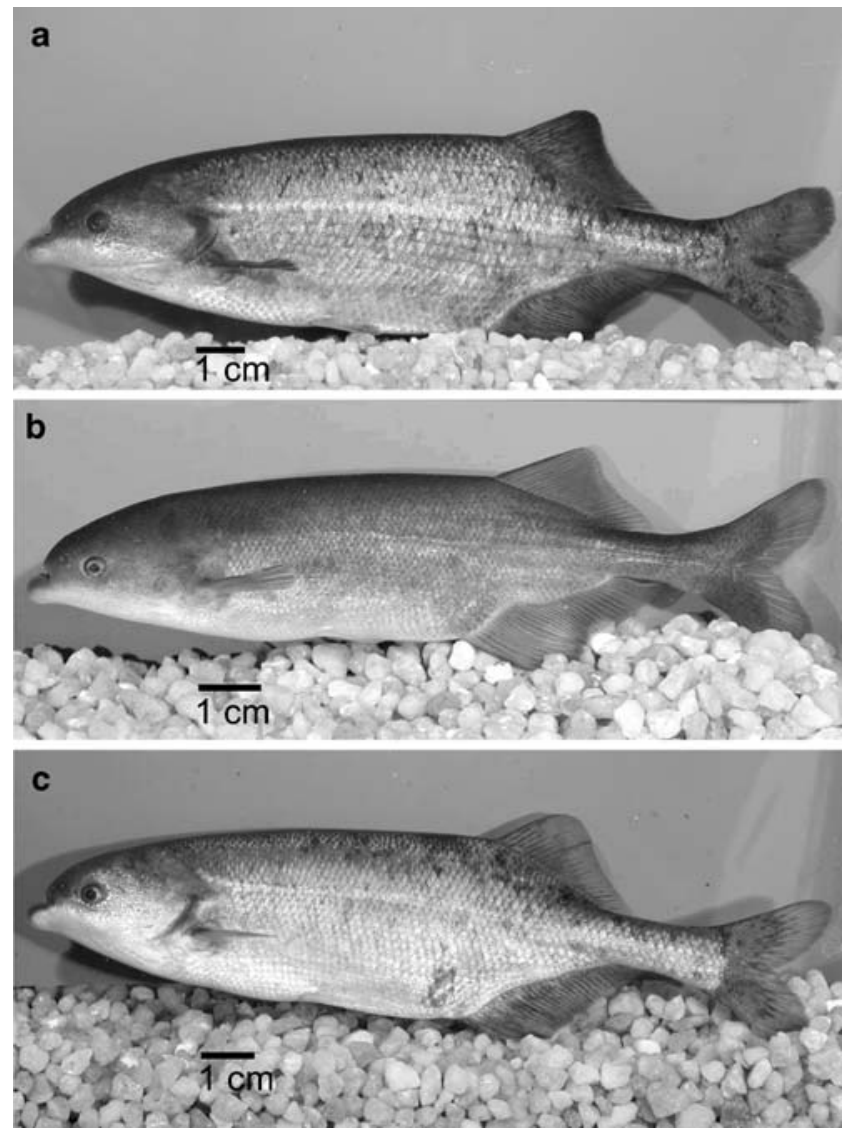

Fig. 1 Photographs of M. macrolepidotus males from a the Upper Zambezi (14.3 cm SL), b the Incomati River system (offspring reared in captivity, $11 \mathrm{~cm} \mathrm{SL}$ ) and $\mathbf{c}$ the Buzi River $(13 \mathrm{~cm} \mathrm{SL})$. All were males as apparent from a kink in their anal fin base. Specimens of the Upper Zambezi have a deeper body, bigger scales and a medium brown coloration with irregular blotches on the sides in contrast to a uniform light brown colour in Incomati River fish were recognised by a kink of their anal fin base whilst that of females was straight (see Kramer 1997).

Animals were kept as follows: water temperature ranged from 22.4 to $26.4^{\circ} \mathrm{C}$ and water conductivity from 96 to $150 \mu \mathrm{S} \mathrm{cm}^{-1}$. The light:dark cycle was $12: 12 \mathrm{~h}$. Animals were fed chironomid larvae (bloodworms) five times per week. The aquarium bottom was covered with sand (1- to 5-mm granulation).

Observation of a stable community of Upper Zambezi fish

Two adult Upper Zambezi males and two females formed a stable community in a 3,000-1 aquarium $(300 \times 100 \times 100 \mathrm{~cm}$ high), which was well-equipped with stones and roots as shelters, and planted with Vesicularia dubyana and Cryptocoryne affinis. Individuals were identified by appearance. The nocturnal behaviour of the fish was videotaped using infrared illumination and an infrared-sensitive camera (Panasonic model FK 69990-IQ, videotape recorder Panasonic model AG 7350, Hifi, S-VHS) for 1-2 h. Additionally, we monitored the time $\widehat{\partial} \mathrm{A}$ and $\rightarrow \mathrm{A}$ remaining in an area from which other individuals were excluded (indication of territoriality vs group cohesion). Sounds were recorded with a hydrophone that was placed about $35 \mathrm{~cm}$ above the aquarium bottom.

\section{Dyadic confrontation experiments}

We observed staged dyadic encounters in a 780-1 experimental aquarium $(240 \times 65 \times 50 \mathrm{~cm}$ high $)$. The $780-1$ experimental tank was divided into two equal compartments by a nylon mesh partition in addition to a solid, opaque plastic partition. At one corner of the partition, several holes (about $1 \mathrm{~cm}$ diameter) facilitated water exchange. Each compartment was equipped with stones and plants ( $V$. dubyana) for shelter. We formed 12 pairs of Upper Zambezi fish (four

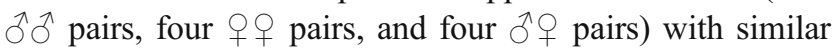
SL. All fish but one exceeded the $40 \%$ SL criterion for sexual maturity (males, SL 12.1-15.9 cm; females, SL 11.8-13.6 cm; see Kramer 1997). We determined SL with an accuracy of $\pm 2 \mathrm{~mm}$ from photographs taken on the day after the dyadic encounters (camera: Nikon Coolpix 990).

Throughout the test series, each individual was paired with a single individual only in the $\bar{\delta} \hat{\sigma}$ or $q 9$ pairs; however, a few individuals were used again to form $\delta^{\wedge} q$ pairs. Before observations, the Upper Zambezi fish were kept separate from their 'partner' for at least 30 days and then considered mutual 'strangers'. Five days before a test, we transferred one individual into each tank compartment. Immediately before dark, we removed both tank partitions to allow the fish to display their unrestricted behaviour, which was observed for $1 \mathrm{~h}$, beginning when both animals left their shelters and confronted one another. When only 
Fig. 2 Partial map of southern Africa showing the sampling localities for individuals of the three different M. macrolepidotus populations indicated as dots. 1 Upper Zambezi River, Lisikili; 2 Buzi River System; 3 Sabie River; 4 Crocodile River (both Incomati River system)

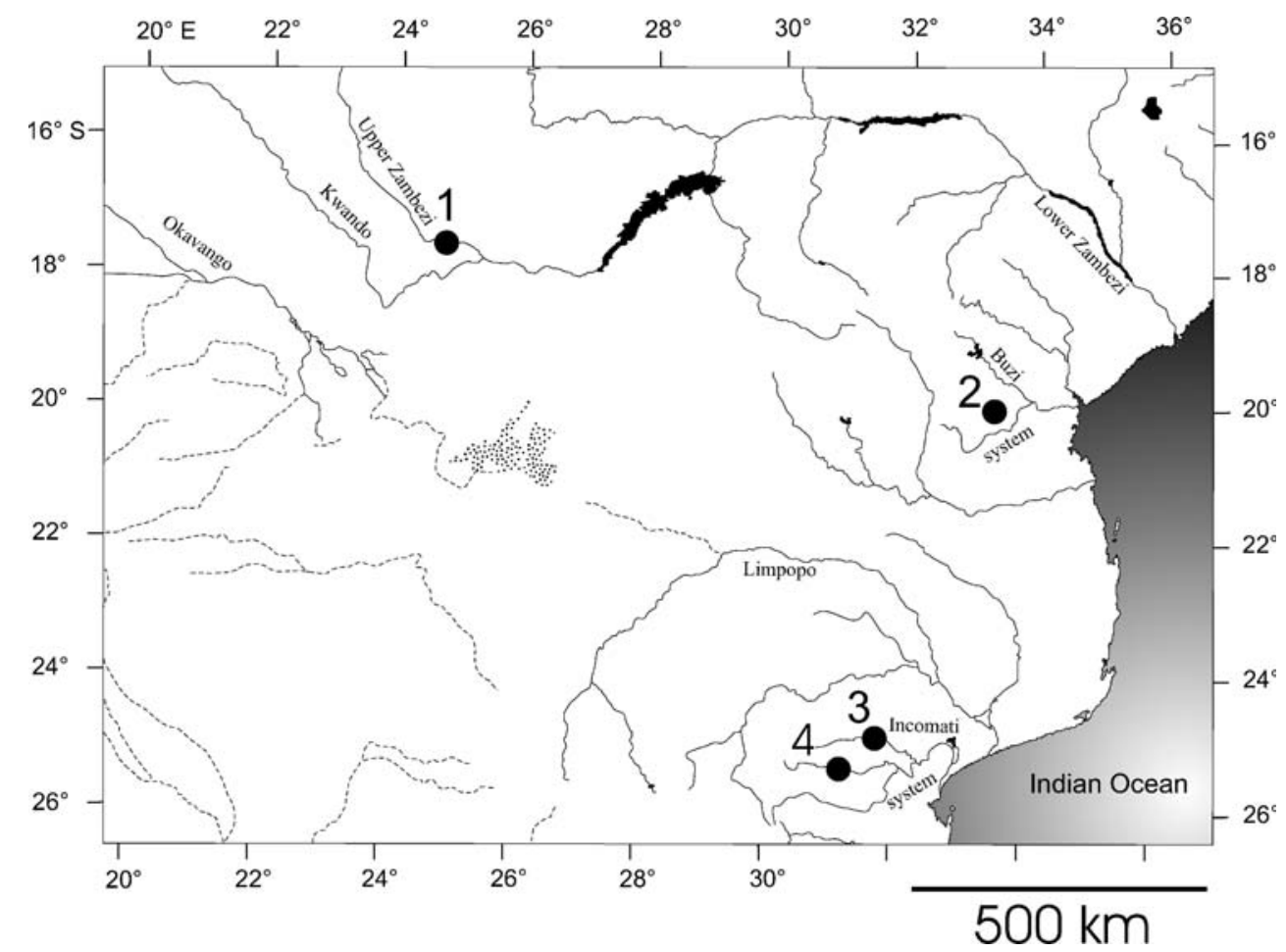

one of the two animals was visible on the video monitor, we alternated observations in 5-min intervals (see Martin and Bateson 1987, pages 48-52). In the centre of the 780-1 observation tank, a hydrophone was positioned about $22 \mathrm{~cm}$ above the bottom at a total water depth of $33 \mathrm{~cm}$. After $1 \mathrm{~h}$, we separated both animals by reintroducing the plastic partitions to prevent the fish from injuring one another.

In the first series of dyadic confrontation experiments, the interacting fish used the whole aquarium space. Therefore, the recorded sound pressure level (SPL) of vocalisations was often very low. To increase the signal-tonoise ratio, we reduced the bottom area of the aquarium to $170 \times 65 \mathrm{~cm}$ by solid plastic partitions whilst recording at the middle mesh partition for $30 \mathrm{~min}$. Subsequently, we removed the mesh partition and observed the unrestricted interactions in three $\widehat{\partial} \hat{\sigma}$, three $q 0$ and three $\hat{\sigma} 0$ Upper Zambezi pairs for another $30 \mathrm{~min}$. Incomati system and Buzi individuals were tested with the same procedure, except that we did not remove the mesh partition. Five Incomati system fish were complete strangers to each other at least for the period they had spent in captivity; six specimens had been kept in the same aquarium and separated at least $22 \mathrm{~h}$ before observations. Four Buzi fish were separated at least $22 \mathrm{~h}$ before observations.

Four Upper Zambezi males and two Upper Zambezi females, which had already been used for the confrontation tests, were kept isolated in 300-1 tanks $(110 \times 55 \times 50 \mathrm{~cm}$ high) to study their rate of sound production during $20 \mathrm{~h}$ of observation.

Acoustical analysis

Vocalisations were recorded with a hydrophone (Brüel \& Kjær 8101, $1 \mathrm{~Hz}-125 \mathrm{kHz}$ frequency response), amplified with a measuring amplifier (Brüel \& Kjær 2610, $2 \mathrm{~Hz}-$ $200 \mathrm{kHz}$ frequency response) and recorded on audio track no. 1 of a videotape recorder. Vocalisations were assigned to individuals using relative SPL that declined with the distance of the fish from the hydrophone. However, when two fish were interacting too closely, it was not possible to assign vocalisations to a specific individual. Only sounds that were assigned to individuals were used for sound analysis. Two consecutive vocalisations from the same fish were separated by at least $500 \mathrm{~ms}$. To reduce low-frequency noise, the amplified hydrophone output was bandpassfiltered (40 Hz-10 kHz passband) using an electronic filter (Wavetek-Rockland Model 452, $24 \mathrm{~dB}$ attenuation/ octave, linear phase response). Vocalisations were digitised at $48 \mathrm{kHz}$ sampling rate and 16-bit vertical resolution using the standard soundcard of an IBM-compatible computer (Pentium IV, 1.7 GHz), controlled by the software AvisoftSASLabPro Version 4.33 (Avisoft Bioacoustics, Berlin, Germany).

Vocalisations with a good signal-to-noise ratio were typically generated within $20 \mathrm{~cm}$ of the hydrophone. Table 1 
summarises all sound characteristics, specifies the data sources and describes the measuring methodology. Temporal parameters such as sound duration, pulse period (PP), and pulse duration were measured visually from sound pressure oscillograms with the cursor and zoom functions of Avisoft. Growl pulse duration was defined as the time period when the sound pulse wave clearly emerged from irregular background noise. Growl PP was measured by visually estimating the period between adjacent peaks of growl pulses during the period of lowest frequency modulation. We averaged 15 pulse durations or PPs per growl. After resampling the vocalisation at $5 \mathrm{kHz}$ using an anti-aliasing filter, we determined the peak-amplitude frequency and the frequency of harmonics with fast Fourier transformation (FFT) amplitude spectra, which were usually generated based on 512 to 16,384 time data points. Therefore, FFT amplitude spectra comprised between 256 to 8,192 frequency data points (resolution, $0.305-9.7 \mathrm{~Hz}$ ). To determine the absolute SPL of vocalisations generated at about $10 \mathrm{~cm}$ of the hydrophone, we measured the relative SPL on the measuring amplifier and calculated the absolute values $(\mathrm{dB}$ re: $1 \mu \mathrm{Pa})$ based on the sensitivity of the hydrophone.

Growl sound analysis is based on six Upper Zambezi males, six Incomati system fish (five males, one female), and two Buzi males. Hoots were recorded from four Upper Zambezi males, five Incomati system fish (four males, one female), and two Buzi fish (one male, one female). The Upper Zambezi, Incomati system and Buzi individuals are represented by at least seven growls each. Four Upper Zambezi individuals are represented by four, four, six and ten hoots each, the Incomati system and the Buzi individuals by at least seven hoots each.

Coefficients of variation $(\mathrm{CV})$ were calculated as $\mathrm{CV}=$ $\mathrm{SD} /$ Mean $\times 100$, using the vocalisations that had already been analysed for descriptive statistics. $\mathrm{CV}_{\mathrm{w}}$ describes the within-individual and $\mathrm{CV}_{\mathrm{b}}$ the between-individual variability of sound characteristics.

\section{Results}

Overt behaviour of Upper Zambezi fish in a stable community of four

Under stable conditions in a 'naturally' equipped large aquarium, adult males and females defended stable territories. For 25 months, ôA occupied an area near the daily feeding spot whilst $O \mathrm{~A}$ occupied an adjoining territory, the boundaries of which were apparent by short agonistic interactions between ${ }^{\top} \mathrm{A}$ and $\rho \mathrm{A}$ (mutual threatening and fighting/circling). At night, fish did not form a group, and we did not observe single-file swimming or communal foraging behaviour. Male $\mathrm{A}$ and $\odot \mathrm{A}$ patrolled their territories, whilst another female ventured there only rarely. During a 3-h nocturnal observation period, o $\mathrm{A}$ remained within her territory for a mean $82 \%$ of the time, and $\delta \mathrm{A}$ remained within his territory for a mean of $89 \%$ of a 1 -h observation time. During another 52 -min observation period, $\partial^{\lambda} \mathrm{A}$ was seen at the territorial boundary to $9 \mathrm{~A}$ for $48 \%$ of the time. Only whilst feeding or shortly thereafter, all individuals gathered near the daily feeding spot at the territorial boundary of $\hat{A}$ and $q \mathrm{~A}$.

Male B was not observed to defend a territory of its own, despite an aquarium capacity of 3,000 1 and $3 \mathrm{~m}^{2}$ bottom area. Male B sometimes approached the territories of $\hat{\delta} \mathrm{A}$ and $q \mathrm{~A}$, who both chased him away at once. Vocalisations accompanied short agonistic interactions between $\widehat{\partial} \mathrm{A}$ and $\uparrow \mathrm{A}$, as well as aggressive behaviours against ${ }^{\lambda} \mathrm{B}$. Several butts/bites (B/B) and rounds of Circling (Circ) preceded mutual threatening, when the opponents were facing each other. During territorial defense, bouts of vocalisations (growls) of variable duration were recorded that accompanied agonistic encounters between male $(\hat{\delta} \hat{\sigma})$ and malefemale $(\hat{\delta}$ 을 pairs at territorial boundaries.

Dyadic confrontation experiments between strangers: overt behaviour

During the day, when tank partitions separated them, both individuals of an M. macrolepidotus pair usually remained inside their shelters. Immediately after dark when the tank partitions were removed, the Upper Zambezi M. macrolepidotus left their shelters. In three out of four interactions between pairs of males, long-lasting, vigorous fights (up to 5 min duration) that included the aggressive motor behaviours parallel display (PD), anti-parallel display (AD) and frontal display (FD) were observed. After facing each other for a moment, both opponents engaged in long-lasting ADs (Fig. 3a) followed by PD (Fig. 3b), sometimes interrupted by short phases of mutual threatening or avoiding. PD alternated with AD. During AD, both fish were orientated in a head-to-tail position, slowly rotating around a common centre and trying to push the rival away or down on the bottom. During PD both fish swam closely together in the same direction at medium or high speed, pushing the opponent sideways or upwards to the water surface, whilst simultaneously directing many bites or butts at the frontal head or operculum of the opponent. AD and PD sometimes alternated with FD (Fig. 3c): two individuals were facing each other, moving back and forth with small, jerky movements. When a fight escalated, individuals attacked one another frontally (Fig. 3d), biting or butting at the head and mouth region of the opponent. This behaviour was accompanied by broadband, click-like sounds that were clearly distinguishable from vocalisations. Frontal attacks 


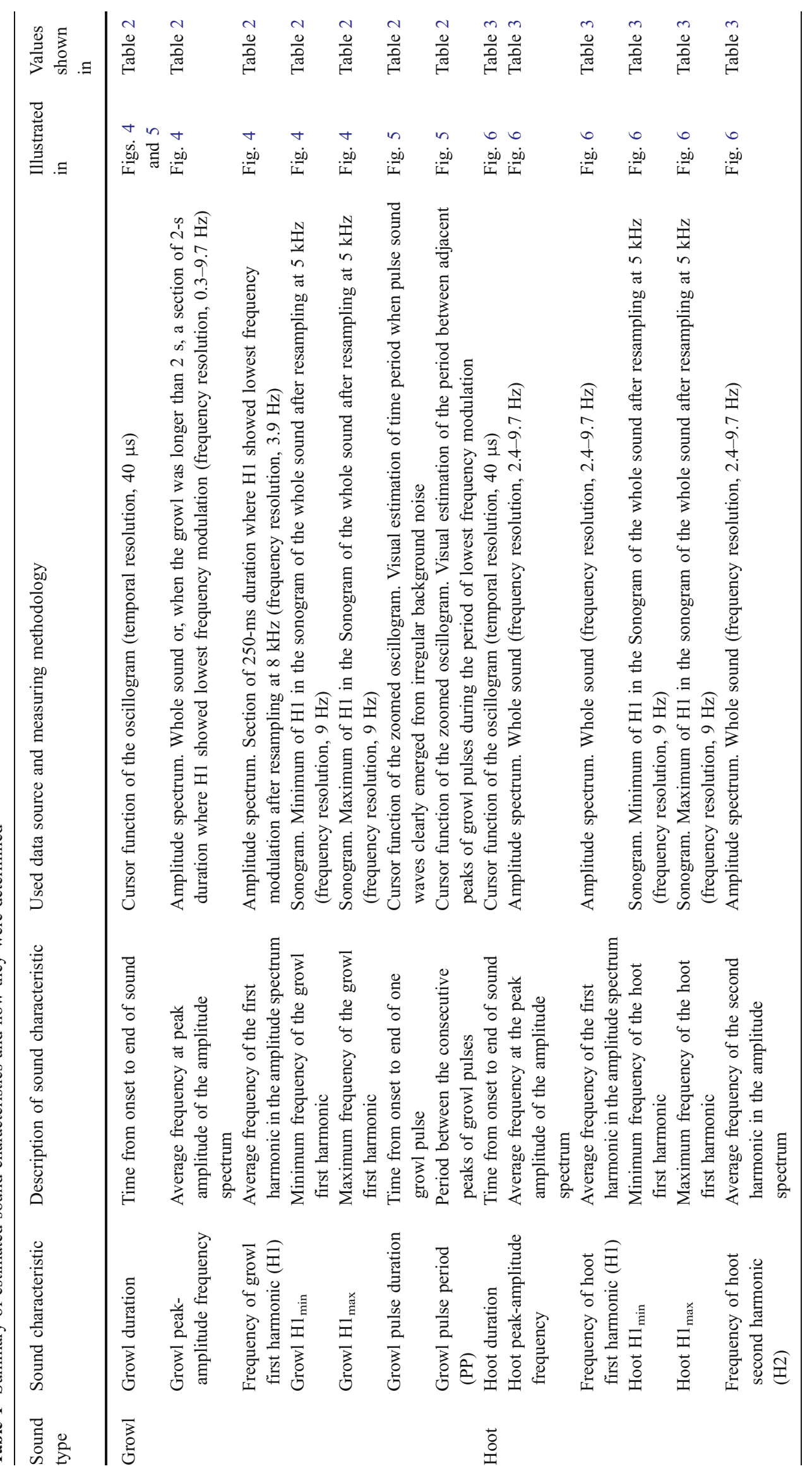


Fig. 3 a-d Typical agonistic motor behaviours displayed by two male Upper Zambezi fish. a Anti-parallel display of vertically orientated fish (ventral view). Both males are closely orientated head-to-tail and rotate slowly around a common centre. b Parallel display (PD). The opponents are swimming closely together in the same direction and mutually try to push the other fish downwards or upwards to the water surface. During PD, many bites or butts are directed against the opponent. c Frontal display. Two fish facing each other within body length moving jerkily back and forth. d Frontal attack. During escalating interactions both fish bite one another into the frontal back or head region. e, f Growl bout recorded from an Upper Zambezi male whilst chasing a male conspecific. e Oscillogram, f sonogram. Sonogram frequency resolution, $11 \mathrm{~Hz}$; temporal resolution, $10.7 \mathrm{~ms}$
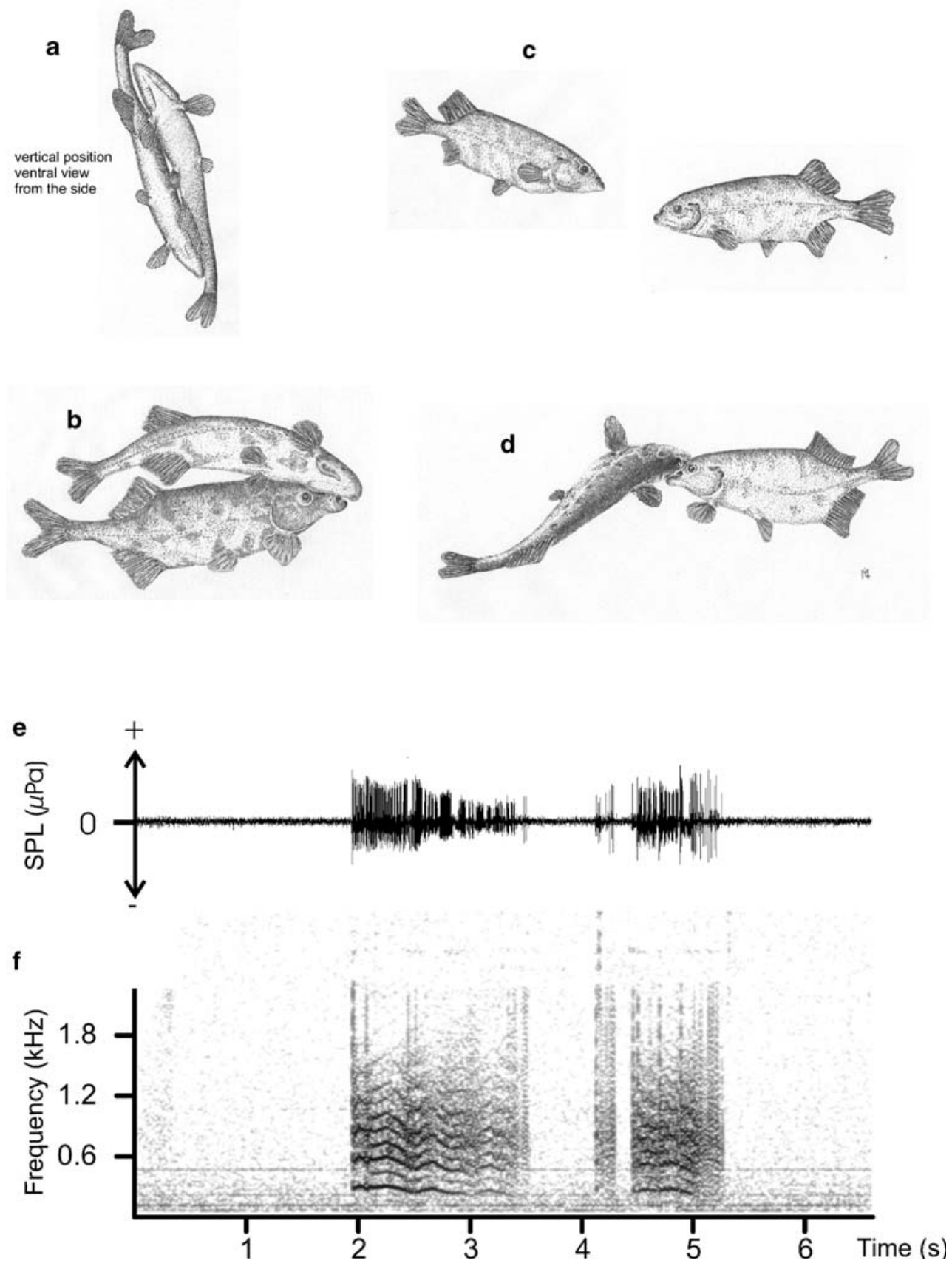

occurred only during protracted fights of similar-sized opponents. In both fish, short retreats were followed by approaching each other again, or by quick, darting movements. Interactions between a pair of females also proceeded aggressively, with even more $\mathrm{B} / \mathrm{Bs}$ per hour than during male encounters (mean number of $\mathrm{B} / \mathrm{Bs}$ per hour averaged over four interactions: $\widehat{\partial} \widehat{\partial}, 32.5$; $ㅇ ㅜ, 76)$. Interestingly, $\mathrm{AD}$ was never observed in female interactions, and PD was observed only twice. Two out of four $\hat{\delta} \phi$ interactions were associated

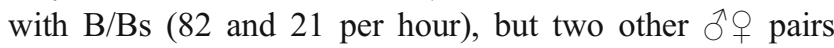
showed very little aggression (1 and $5 \mathrm{~B} / \mathrm{Bs}$ per hour).
With the mesh partition present, the behaviour of Buzi and Incomati fish was at least as aggressive as that observed in Upper Zambezi males, presumably because there was less risk. Paired Incomati system and Buzi fish also interacted clearly at the mesh partition, displaying motor behaviours similar to those seen in Upper Zambezi fish. Long-lasting PD (only for the short distance along the mesh partition) alternated with $\mathrm{FD}$, and subsequent short retreats were followed by quick attacks (Dart) and many B/ Bs directed against the opponent through the mesh partition. 
Dyadic confrontation experiments between strangers: vocalisations

We recorded two types of vocalisations during agonistic interactions between pairs of males and also during the less violent male-female interactions.

Growl The growl sound in Upper Zambezi males (Figs. 3e,f, 4 and 5, Table 2) is composed of a succession of acoustic pulses with a noisy harmonic structure, as revealed by sonograms. In addition to a slightly frequencymodulated first harmonic (fundamental frequency, H1), higher harmonics were sometimes present (Fig. 4a, $\mathrm{a}^{\prime}$ ). The fundamental frequency corresponded well to the PP (Fig. 5a'), but was not always the component of highest intensity (peak-amplitude frequency) between and within individuals. Moreover, some growls revealed no harmonic structure at all. The absolute SPL of a growl generated at about $10 \mathrm{~cm}$ distance from the hydrophone was about $105 \mathrm{~dB}$ re: $1 \mu \mathrm{Pa}$ at a background noise level of $80 \mathrm{~dB}$ re: $1 \mu \mathrm{Pa}$.

The growls of six Incomati system fish (five males and one female, recorded during six $\widehat{\jmath} \cap$ encounters) and two
Fig. 4 Acoustic properties of the growl. Examples for Upper Zambezi males (a, $\left.\mathbf{a}^{\prime}\right)$, Incomati system males $\left(\mathbf{b}, \mathbf{b}^{\prime}\right)$ and Buzi males $\left(\mathbf{c}, \mathbf{c}^{\prime}\right)$. a The sonogram of a growl generated by a Upper Zambezi male shows clear harmonic structure, with a strong first harmonic $(\mathrm{Hl})$ at $232 \mathrm{~Hz}$ also representing the component of highest intensity (peak-amplitude frequency). Higher harmonics were seen at $465 \mathrm{~Hz}$ (H2), $705 \mathrm{~Hz}(H 3)$ and $937 \mathrm{~Hz}$ (H4). Other individuals from the Upper Zambezi fish, as well as the Incomati system fish and Buzi fish often generated growls with a less pronounced harmonic structure (see $\mathbf{b}$ and $\mathbf{c}$ ). The sonograms are based on 1,024point FFTs, with a frame size of $50 \%, 93.75 \%$ frame overlap, and Hamming Window applied. Frequency resolution was $11 \mathrm{~Hz}$, time resolution $5.3 \mathrm{~ms}$, filter pass-band, $40 \mathrm{~Hz}-10 \mathrm{kHz}$ a
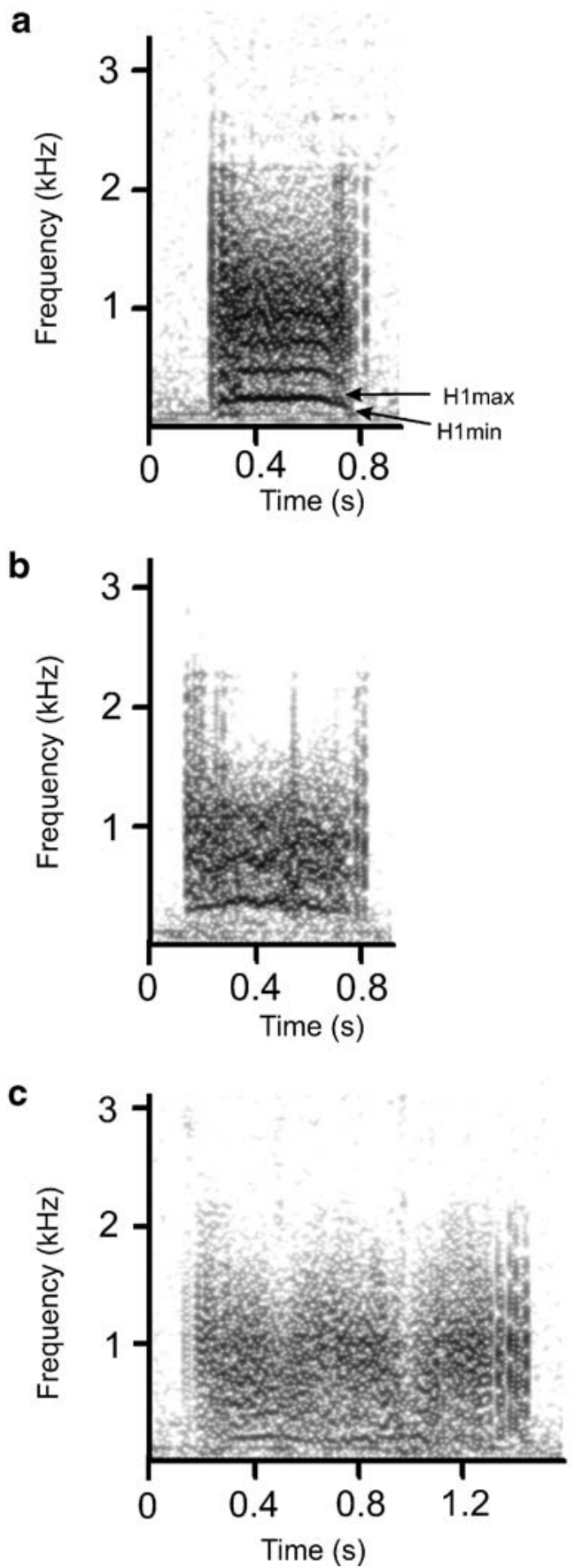

$a^{\prime}$

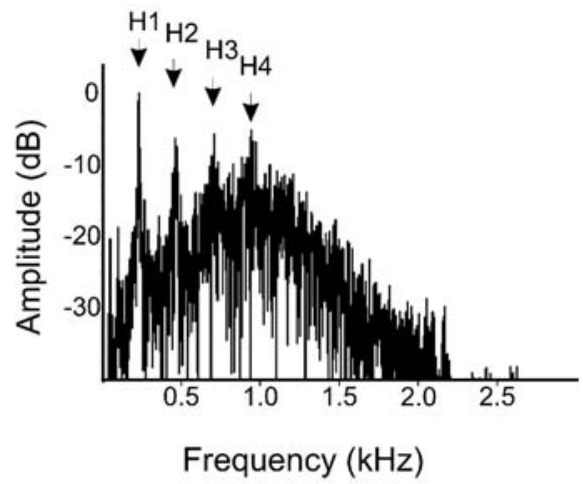

$\mathbf{b}^{\prime}$

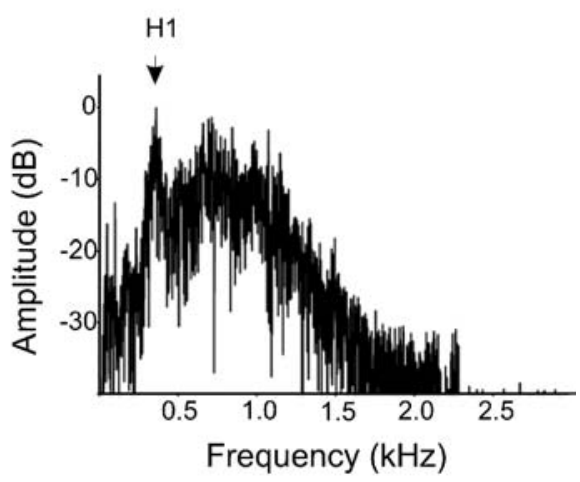

ć

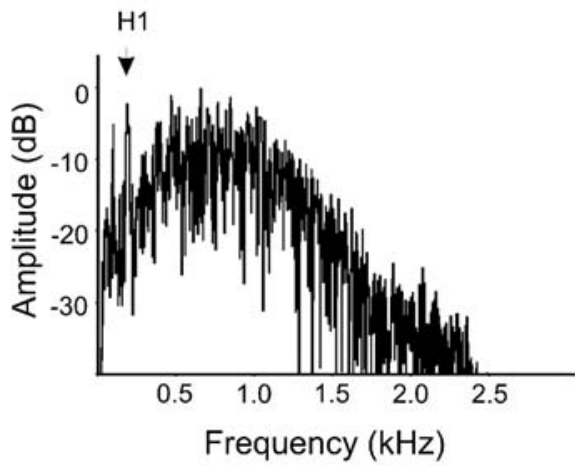


a

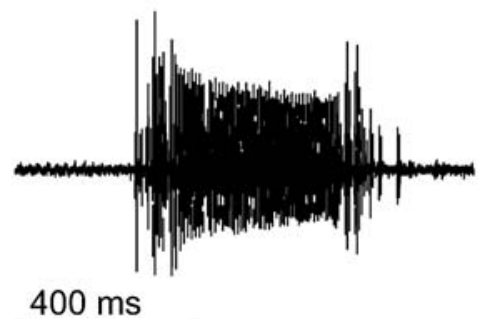

$400 \mathrm{~ms}$

b

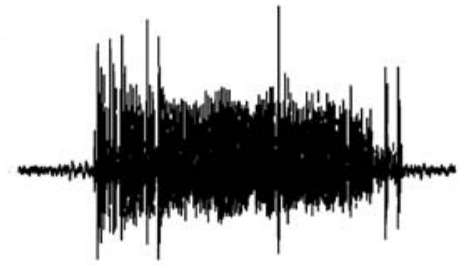

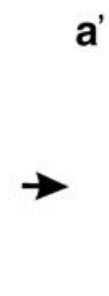
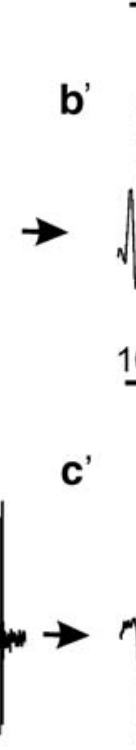

10

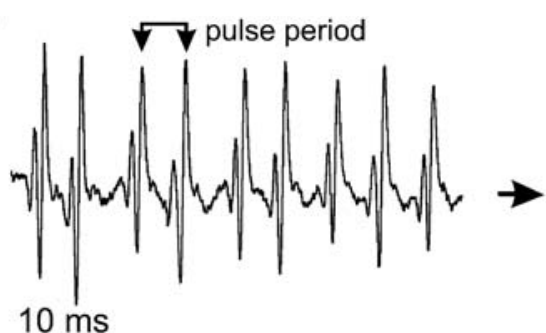

$10 \mathrm{~ms}$

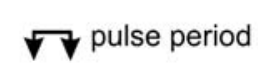

$\sqrt{ }$ pulse period

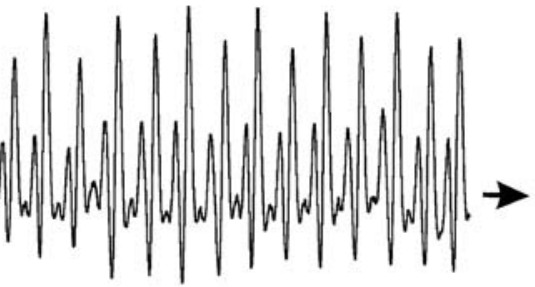

b"

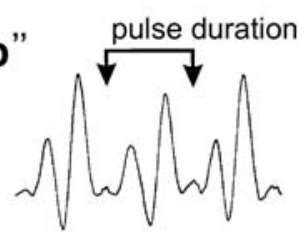

$2.5 \mathrm{~ms}$ a"

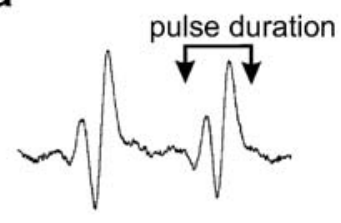

$2.5 \mathrm{~ms}$
$400 \mathrm{~ms}$

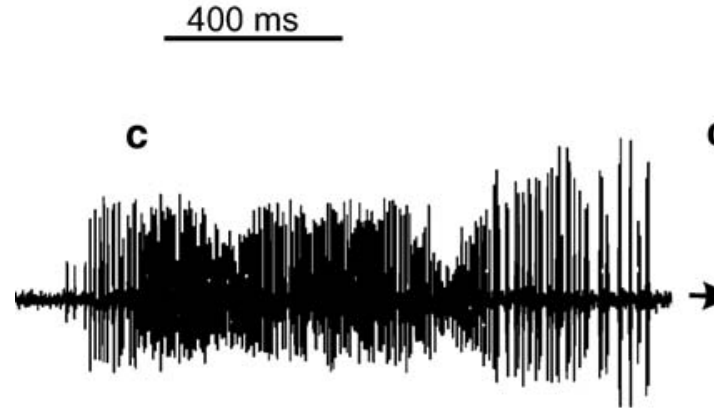

$400 \mathrm{~ms}$
$10 \mathrm{~ms}$
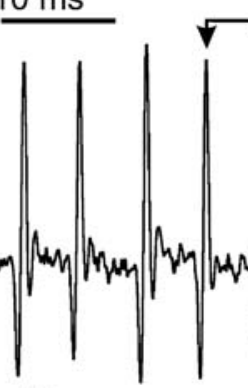

pulse period
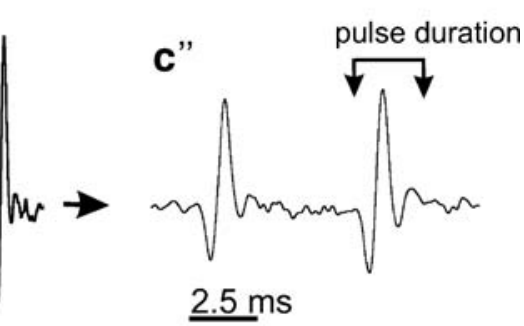

$\underline{2.5 \mathrm{~ms}}$

Fig. 5 Details of the waveform of the growls in Fig. 4 at high temporal resolution, showing single acoustic pulses. a-a" Upper Zambezi male; many acoustic pulses are repeated at a mean PP of $4.3 \mathrm{~ms}$. b-b" Incomati system male, PP=2.7 ms. c-c" Buzi male, PP=5.27 ms

Buzi fish (two males recorded during two $\widehat{\jmath} \uparrow$ encounters) that were also displayed during dyadic confrontation tests were basically similar to those observed in Upper Zambezi males (see Figs 4 and 5; Table 2).

We tested the hypothesis that there are no group (origin)specific differences present between growls recorded from Upper Zambezi and South African M. macrolepidotus in any one of the characteristics: total duration, pulse duration, $\mathrm{PP}$ and $\mathrm{H} 1$ by a multivariate analysis of variance (MANOVA). The null hypothesis of no difference between origins was rejected $\left(F_{4,5}=11.28, P=0.0036\right.$ for all four test variables, Wilk's Lambda, Roy's Greatest Root, HotellingLawley Trace, and Pillai Trace). Subsequent univariate ANOVAs showed a significant difference between origins for a higher $\mathrm{H} 1$ frequency $\left(F_{1,10}=37.751, P=0.0001\right)$ in Incomati system fish than Upper Zambezi fish. It is not unexpected that $\mathrm{H} 1_{\min }$ and $\mathrm{H} 1_{\max }$ were also higher in Incomati system fish compared to Upper Zambezi males (Table 2).

Ten growls generated by one Buzi male of $13 \mathrm{~cm}$ SL were of clearly longer duration (mean, $2.02 \pm$ SE $0.378 \mathrm{~s}$ ) with higher PPs (mean, $6.38 \pm$ SE $0.35 \mathrm{~ms}$ ), but similar pulse duration (mean, $2.8 \pm \mathrm{SE} 0.07 \mathrm{~ms}$ ) than those of six
Incomati system fish (five males and one female) and six Upper Zambezi males. Only four of this Buzi male's growls revealed an $\mathrm{H} 1$, and its mean frequency was the lowest for all fish studied $(196 \mathrm{~Hz})$. The other Buzi male's $(9.7 \mathrm{~cm}$ $\mathrm{SL})$ growls of still longer duration $(2.36 \pm \mathrm{SE} 0.55 \mathrm{~s})$ were composed of a series of pulses (mean pulse duration: $2.2 \pm$ SE $0.13 \mathrm{~ms})$ with a highly variable PP $(6.23 \pm$ SE $0.8 \mathrm{~ms})$ but lacked a harmonic structure.

We studied the within- and between-individual variability of growl characteristics by calculating the $\mathrm{CV}_{\mathrm{w}}$ and $\mathrm{CV}_{\mathrm{b}}$ in Upper Zambezi and Incomati system individuals, from which between 6 and 15 growl sound characteristics were analysed (Table 4). At $\mathrm{CV}_{\mathrm{b}} / \mathrm{CV}_{\mathrm{w}}>1$, a given sound characteristic could theoretically function as an individual signature. Only the growl characteristics pulse duration in Upper Zambezi males and PP in Incomati system fish satisfied this requirement.

Hoot We recorded so-called hoot sounds that were accompanied by quick approaching behaviours (Dart) and by $\mathrm{AD}$ in freely interacting Upper Zambezi- $\hat{\partial} \sigma^{\hat{\alpha}}$ pairs, whereas in Buzi ( $\widehat{\sigma} \phi$ and $\phi++$ ) and Incomati system ( $\widehat{\partial}$, $\hat{\delta} \bigcirc$ and $ㅇ$ ) interactions at a plastic mesh partition, hoots were recorded during Dart, FD and PD (Fig. 6, Table 3). 
Table 2 Descriptive statistics of the growl for Upper Zambezi fish, Incomati system fish, and Buzi fish

\begin{tabular}{|c|c|c|c|c|c|c|}
\hline & Growl duration $^{\mathrm{a}}(\mathrm{ms})$ & Pulse duration ${ }^{\mathrm{a}}(\mathrm{ms})$ & Pulse period ${ }^{\mathrm{a}}(\mathrm{ms})$ & $\mathrm{H} 1^{\mathrm{a}}(\mathrm{Hz})$ & $\mathrm{H} 1_{\min }(\mathrm{Hz})$ & $\mathrm{H} 1_{\max }(\mathrm{Hz})$ \\
\hline \multicolumn{7}{|c|}{ Upper Zambezi males $(n=6)$} \\
\hline Mean $^{\mathrm{b}} \pm \mathrm{SE}$ & $1,306 \pm 191.0$ & $2.4 \pm 0.130$ & $4.12 \pm 0.166$ & $266 \pm 8.92$ & $215 \pm 9.74$ & $297 \pm 9.47$ \\
\hline Minimum $^{\mathrm{c}}$ & 777 & 2.0 & 3.75 & 237 & 191 & 277 \\
\hline Maximum $^{c}$ & 2,114 & 2.8 & 4.89 & 300 & 259 & 326 \\
\hline \multicolumn{7}{|c|}{ Incomati system fish ( $n=6$; five males and one female) } \\
\hline $\mathrm{Mean}^{\mathrm{b}} \pm \mathrm{SE}$ & $1,284 \pm 331.5$ & $2.57 \pm 0.105$ & $4.05 \pm 0.503$ & $355 \pm 11.3$ & $273 \pm 11.56$ & $375 \pm 8.81$ \\
\hline Minimum $^{c}$ & 359 & 2.34 & 2.86 & 321 & 236 & 350 \\
\hline Maximum $^{\mathrm{c}}$ & 2593 & 3.05 & 6.04 & 392 & 319 & 409 \\
\hline \multicolumn{7}{|l|}{ Buzi males } \\
\hline \multicolumn{7}{|l|}{ Male 01} \\
\hline $\operatorname{Mean}^{\mathrm{d}} \pm \mathrm{SE}$ & $2,022 \pm 378$ & $2.8 \pm 0.07$ & $6.38 \pm 0.356$ & $196 \pm 4.349$ & $180 \pm 2.887$ & $203 \pm 3.146$ \\
\hline Min-Max of ( $x$ growls) & $893-4,430(10)$ & $2.47-3.12(10)$ & $5.27-9.32(10)$ & $185-205$ (4) & $175-185$ (4) & $195-205(4)$ \\
\hline \multicolumn{7}{|l|}{ Male 02} \\
\hline $\operatorname{Mean}^{\mathrm{d}} \pm \mathrm{SE}$ & $2,367 \pm 553$ & $2.2 \pm 0.13$ & $6.23 \pm 0.806$ & - & - & - \\
\hline Min-Max of ( $x$ growls) & $470-5,310(10)$ & $1.56-2.93(10)$ & $2.87-10.35(10)$ & - & - & - \\
\hline
\end{tabular}

Water temperature, $25.1 \pm \mathrm{SD} 0.18^{\circ} \mathrm{C}$ (Upper Zambezi males) and $24.7 \pm \mathrm{SD} 0.15^{\circ} \mathrm{C}$ (Incomati fish). All sounds were passband-filtered at $40 \mathrm{~Hz}-$ $10 \mathrm{kHz}$.

${ }^{a}$ Variables used for the comparison of the growls of Incomati system $(n=6)$ and Upper Zambezi fish $(n=6)$ by MANOVA and ANOVAs. For results, see text.

${ }^{\mathrm{b}}$ Each fish represented by the average of at least seven of its sounds. Upper Zambezi males, 13.2-15.9 cm SL; Incomati system animals, 11.0$15.9 \mathrm{~cm} \mathrm{SL}$; Buzi animals, 9.7 and $13 \mathrm{~cm} \mathrm{SL}$

${ }^{\mathrm{c}}$ Minimum or maximum value amongst the means for all six individuals (at least seven sounds per individual averaged)

${ }^{\mathrm{d}}$ Ten growls averaged (except for $\mathrm{H} 1, \mathrm{H} 1_{\min }$, and $\mathrm{H} 1_{\max }$ that were apparent only in four growls of Buzi male 01 and in none of Buzi male 02 )

The hoot, as generated by all three groups, differed from the growl by a shorter total sound duration, a tonal sound quality and sinusoidal waveform (visible when zoomed; Fig. $\left.6 \mathrm{a}^{\prime}-\mathrm{c}^{\prime}\right)$. With an SPL of about $109 \mathrm{~dB}$ re: $1 \mu \mathrm{Pa}$, the hoot was much louder than an average growl.
All hoots showed a frequency-modulated fundamental (H1) that was initially rising and then falling off again (Fig. 6). In all three groups, H1 was the component of strongest intensity. Frequencies did not seem to differ substantially (and the second harmonics, H2, were approx-

Table 3 Descriptive statistics of the hoot for Upper Zambezi fish, Incomati system fish and Buzi fish

\begin{tabular}{|c|c|c|c|c|c|}
\hline & Hoot duration (ms) & $\begin{array}{l}\text { Spectral frequency } \\
\text { of peak amplitude/H1 }(\mathrm{Hz})\end{array}$ & $\mathrm{H} 1_{\min }(\mathrm{Hz})$ & $\mathrm{H} 1_{\max }(\mathrm{Hz})$ & $\mathrm{H} 2(\mathrm{~Hz})$ \\
\hline \multicolumn{6}{|c|}{ Upper Zambezi males $(n=3)$} \\
\hline $\operatorname{Mean}^{\mathrm{a}} \pm \mathrm{SE}$ & $172 \pm 35.9$ & $245 \pm 25.8$ & $190 \pm 20.4$ & $258 \pm 25$ & $506 \pm 65.7$ \\
\hline Minimum $^{\mathrm{b}}$ & 111 & 207 & 147 & 220 & 436 \\
\hline Maximum $^{\mathrm{b}}$ & 272 & 321 & 246 & 331 & 638 \\
\hline \multicolumn{6}{|c|}{ Incomati system fish ( $n=5$; four males and one female) } \\
\hline $\operatorname{Mean}^{\mathrm{a}} \pm \mathrm{SE}$ & $161 \pm 33.7$ & $326 \pm 25.7$ & $257 \pm 25.9$ & $356 \pm 17.9$ & $626 \pm 43.5$ \\
\hline Minimum $^{\mathrm{b}}$ & 78 & 265 & 195 & 306 & 520 \\
\hline Maximum $^{2}$ & 247 & 389 & 325 & 403 & 727 \\
\hline \multicolumn{6}{|l|}{ Buzi fish } \\
\hline \multicolumn{6}{|l|}{ Male 02} \\
\hline $\operatorname{Mean}^{\mathrm{a}} \pm \mathrm{SE}$ & $103 \pm 9.08$ & $315 \pm 7.14$ & $252 \pm 7.94$ & $325 \pm 6.06$ & $633 x \pm 11.22$ \\
\hline Min-Max of ( $x$ hoots $)$ & $72-136(8)$ & 294-338 (8) & $224-283(8)$ & $302-341(8)$ & $597-669(8)$ \\
\hline \multicolumn{6}{|l|}{ Female 01} \\
\hline $\operatorname{Mean}^{\mathrm{a}} \pm \mathrm{SE}$ & $145 \pm 9.8$ & $196 \pm 3.87$ & $137 \pm 3.145$ & $208 \pm 3.56$ & $392 \pm 8.44$ \\
\hline Min-Max of ( $x$ hoots) & $107-193(10)$ & $182-220(10)$ & $126-156(10)$ & 195-224 (10) & $348-440$ \\
\hline
\end{tabular}

Water temperature, $24.8 \pm \mathrm{SD} 0.6^{\circ} \mathrm{C}$ Upper Zambezi fish and $24.7 \pm \mathrm{SD} 0.2^{\circ} \mathrm{C}$ Incomati system fish. All sounds were passband-filtered at $40 \mathrm{~Hz}-$ $10 \mathrm{kHz}$.

${ }^{a}$ Each fish represented by the average of four, six, and ten of its hoots in Upper Zambezi males, seven hoots in Incomati system fish, and eight and ten hoots in the two Buzi fish, respectively

${ }^{\mathrm{b}}$ Minimum or maximum value amongst the means for all individuals 
Table 4 Within- and between-individual variability of growl sounds for Upper Zambezi males (six males for the growl, two males for the hoot) and of the growl and hoot sound for Incomati system fish (four males and one female) as measured by the coefficient of variation

\begin{tabular}{|c|c|c|c|c|c|c|c|c|}
\hline \multirow[t]{2}{*}{ Sound characteristic } & \multicolumn{4}{|c|}{ Upper Zambezi males } & \multicolumn{4}{|c|}{ Incomati system fish } \\
\hline & $\begin{array}{l}\text { Mean } \\
\text { within-male } \\
\text { CV (\%) }\end{array}$ & $\begin{array}{l}\text { Range of } \\
\text { within-male } \\
\text { CV (\%) }\end{array}$ & $\begin{array}{l}\text { Between- } \\
\text { male CV } \\
(\%)\end{array}$ & $\begin{array}{l}\text { Ratio } \\
\mathrm{CV}_{\mathrm{b}} / \\
\mathrm{CV}_{\mathrm{w}}\end{array}$ & $\begin{array}{l}\text { Mean within- } \\
\text { individual } \mathrm{CV} \\
(\%)\end{array}$ & $\begin{array}{l}\text { Range of } \\
\text { within- } \\
\text { individual CV } \\
(\%)\end{array}$ & $\begin{array}{l}\text { Between- } \\
\text { individual } \\
\mathrm{CV}(\%)\end{array}$ & $\begin{array}{l}\text { Ratio } \\
\mathrm{CV}_{\mathrm{b}} / \\
\mathrm{CV}_{\mathrm{w}}\end{array}$ \\
\hline Growl duration & 52.1 & $47.6-62.3$ & 35.1 & 0.68 & 52.81 & $34.48-80.67$ & 63.23 & 1.19 \\
\hline Growl pulse duration & 11.7 & $6.3-18.93$ & 13.2 & 1.12 & 8.93 & $5.01-15.02$ & 9.72 & 1.08 \\
\hline Growl pulse period & 17.65 & $7.03-42.15$ & 9.86 & 0.55 & 24.34 & $13.01-54.42$ & 29.62 & 1.21 \\
\hline Growl H1 & 9.3 & $6.41-14.82$ & 8.21 & 0.88 & 12.33 & $6.28-23.63$ & 7.8 & 0.63 \\
\hline Growl $\mathrm{H} 1_{\min }$ & 10.18 & $5.65-19.71$ & 11.05 & 1.08 & 15.33 & $6.65-28.74$ & 10.36 & 0.67 \\
\hline Growl $\mathrm{H} 1_{\max }$ & 10.56 & $6.51-15.2$ & 7.79 & 0.73 & 14.7 & $8.34-24.77$ & 5.73 & 0.38 \\
\hline Hoot duration & - & $28.9-34.2 *$ & 31.20 & 0.99 & 27.76 & $25.39-32.41$ & 46.58 & 1.6 \\
\hline Hoot H1 & - & $6.8-17.1^{*}$ & 11.77 & 0.98 & 7.82 & $4.58-9.84$ & 17.48 & 2.23 \\
\hline Hoot $\mathrm{H} 1_{\min }$ & - & $12.4-20.7^{*}$ & 16.08 & 0.97 & 13.05 & $6.93-17.36$ & 22.17 & 1.69 \\
\hline Hoot $\mathrm{H} 1_{\max }$ & - & $6.0-16.7^{*}$ & 11.12 & 0.98 & 6.09 & $4.4-9.54$ & 11.23 & 1.84 \\
\hline Hoot H2 & - & $10.7-12.7^{*}$ & 11.69 & 0.99 & 7.11 & $4.43-8.67$ & 15.49 & 2.17 \\
\hline
\end{tabular}

Sound characteristics that are potentially individual markers are presented in bold print $\left(\mathrm{CV}_{\mathrm{b}} / \mathrm{CV}_{\mathrm{w}}>1.1\right)$.

${ }^{a}$ Only two Upper Zambezi males generated $\geq 6$ hoots each; an individual $\mathrm{CV}_{\mathrm{w}}$ range (and no mean $\mathrm{CV}_{\mathrm{w}}$ ) is given for each.

imately found where expected). Testing for differences between Incomati system and Upper Zambezi fish by inferential statistics was not possible because of the low number of hoots, which only four Upper Zambezi males generated. Hoots from Buzi male 02 and female 01 were similar to those from Incomati system and Upper Zambezi fish in duration. The $\mathrm{H} 1, \mathrm{H} 1_{\min }$ and $\mathrm{H} 1_{\max }$ values were also similar to those recorded from Incomati system and Upper Zambezi fish in the male, but lower when recorded from the female (Table 3).

Hoots generated by the Incomati system fish (four males and one female) showed high inter-individual variability in some hoot characteristics. For example, hoots from a small male $(9.3 \mathrm{~cm} \mathrm{SL})$ had a mean $\mathrm{H} 1$ frequency of $365 \pm \mathrm{SE} 4.4 \mathrm{~Hz}$ in contrast to $265 \pm \mathrm{SE}$ $10.6 \mathrm{~Hz}$ in the biggest male $(21 \mathrm{~cm} \mathrm{SL})$. The $\mathrm{CV}_{\mathrm{b}}$ was higher than $\mathrm{CV}_{\mathrm{w}}$ for all hoot characteristics analysed $\left(\mathrm{CV}_{\mathrm{b}} / \mathrm{CV}_{\mathrm{w}} \geq 1.6\right.$, Table 4).

Dyadic confrontation experiments between strangers: growl rate in Upper Zambezi fish

In contrast to the many growls generated by four $\delta \hat{\delta}$ (mean, 138 growls/h) and four $\hat{\jmath} 0$ pairs (mean, 148 growls/h), we observed only a few growls in four 우우 pairs (mean, 7.5 growls $/ \mathrm{h}$ ), and still fewer in isolated Upper Zambezi fish (mean, 0.3 growls/h; Fig. 7a). Whilst growls accompanied aggressive behaviours in most $\hat{\partial} \hat{\sigma}$ encounters, in $\hat{\alpha}$ o 9 pairs the males also growled during nonthreatening behaviours. In spite of intense aggression also observed in $q$ ㅇ pairs, Upper Zambezi females generated only few growls of shorter duration, longer PPs, and of weaker intensity. Isolated Upper Zambezi females did not vocalise at all, whereas one isolated Upper Zambezi male once produced six growls per hour.

Dyadic confrontation experiments between strangers: motor activities during growl production in Upper Zambezi fish

Growls occurred when two individuals interacted closely at a distance of no more than about $30 \mathrm{~cm}$. Most of the growls occurred during Approach (App; $\widehat{\jmath}, 34 \%$; $\hat{\jmath}+, 53 \%$ ), Following one another ( $\mathrm{Fo}$; $\hat{\partial} \hat{\delta}, 19 \%$; $\hat{\partial}$ ㅇ, $15 \%$ ), Circling (Circ; $\hat{\partial} \hat{\partial}, 12 \%$; $\widehat{\partial}+, 14 \%$ ) and Remaining next to one

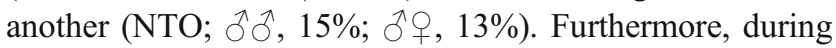
PD $(\hat{\jmath} \hat{\jmath}, 6.8 \%$; $\hat{\jmath}+, 2.4 \%$ ), growls were more often generated in $\widehat{\partial} \hat{\sigma}$ than $\widehat{\partial} \phi$ interactions. Only in $\widehat{\partial} \hat{\delta}$ interactions did we observe growls during FD (5\%) and $\mathrm{AD}(2 \%)$, because FD and AD were not observed in female pairs (Fig. 7b). M. macrolepidotus from the Incomati and Buzi River system that interacted at the mesh partition produced growls during similar displays.

During one Upper Zambezi $\delta P$ interaction, the male aggressively chased away the female from the bottom region. After a few minutes, the male stopped his chasing behaviour, and the female approached the male repeatedly. This caused the male to growl intensely. Subsequent to or alternating with phases of frequent growling, the individuals adopted a posture approximately in parallel to one another and close to a tank wall, with anal fin regions in contact, that was similar to the spawning posture documented for M. macrolepidotus from the Incomati system (see Fig. 9c in Werneyer and Kramer 2005), but no eggs were laid. This 'courtship posture' was repeated several times within several minutes. 
a

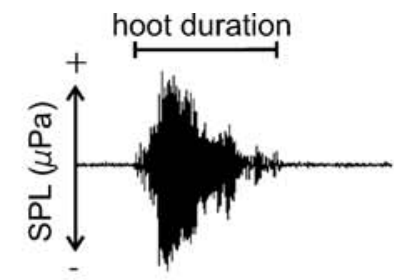

a"

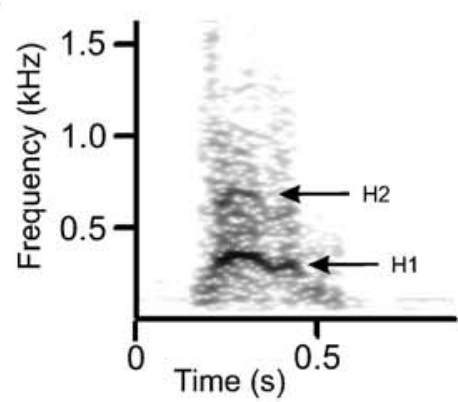

b

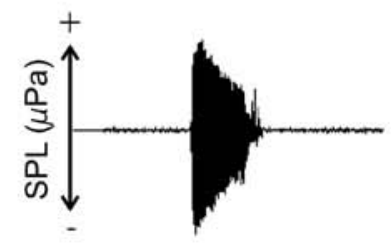

b"

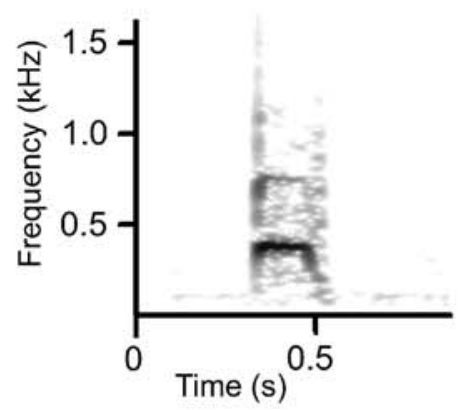

c

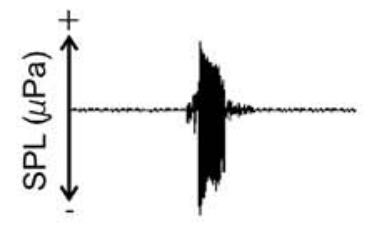

c"

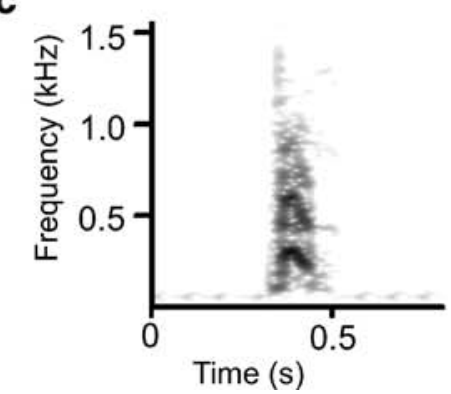

a

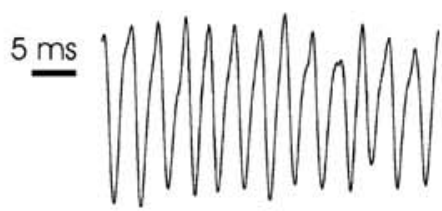

$a^{\cdots}$

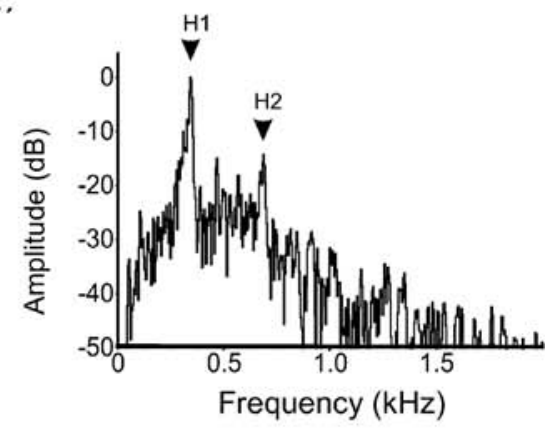

b'

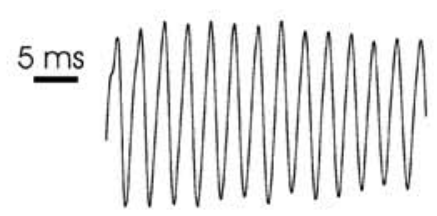

b'.
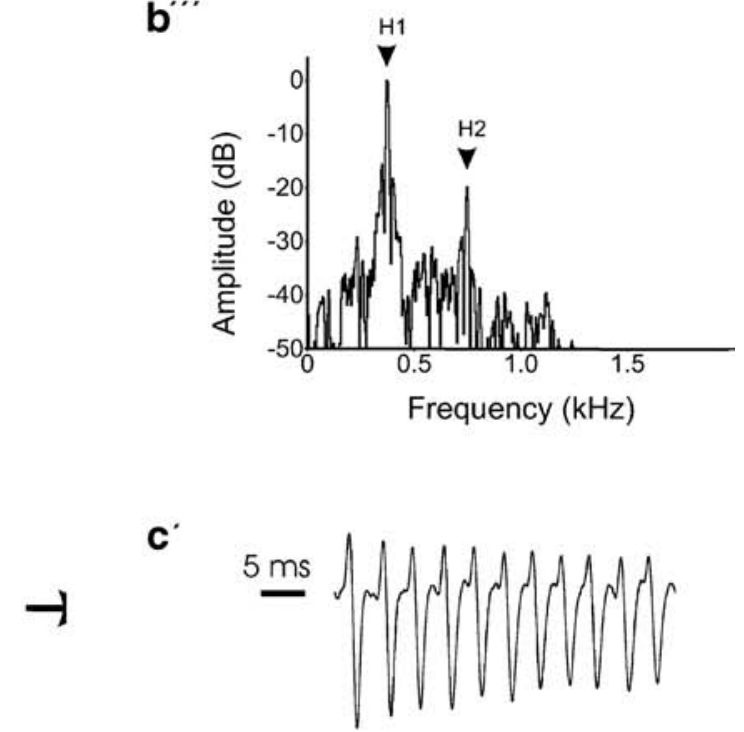

c $^{\cdots}$

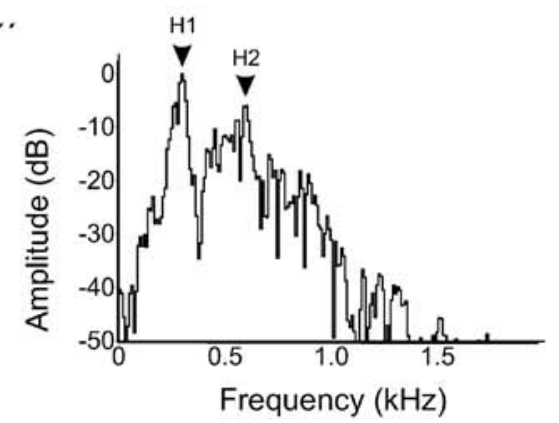


Fig. 6 Hoots recorded from a Upper Zambezi, b South African and c Buzi fish. The sonogram in a" reveals a frequency-modulated first harmonic (H1, fundamental frequency). This hoot showed an $\mathrm{H} 1$ of $341 \mathrm{~Hz}$ and a weaker second harmonic (that occurred at $682 \mathrm{~Hz}$ in the amplitude spectrum $\left.\mathbf{a}^{\prime \prime \prime}\right)$. The sonograms are based on 1,024-point FFTs, $50 \%$ frame size, $96.8 \%$ overlap, and Hamming Window applied. Frequency resolution, $7 \mathrm{~Hz}$; temporal resolution, $4 \mathrm{~ms}$

\section{Discussion}

In a large aquarium adult individuals from the Upper Zambezi River in a stable community of four showed territorial behaviour that was accompanied by vocalisations, and were not facultatively schooling like juvenile Marcusenius cyprinoides (Moller 1976), Marcusenius senegalensis (Scheffel and Kramer 1997), and adult Cyphomyrus discorhynchus (Scheffel and Kramer 2006). M. macrolepidotus from all three origins of the present study vocalised growls when confronting a stranger conspecific in staged, dyadic encounters, and for Upper Zambezi males, also during non-threatening male-female interactions.

Amongst three allopatric M. macrolepidotus populations, the harsh growl was of basically similar acoustic structure, but Incomati fish differed from Upper Zambezi males in their higher frequency of the first growl harmonic, whilst the two Buzi males that vocalised displayed the longest growl duration and PP. Thus, origin-specific growls indicate allopatric differentiation at least between Upper Zambezi and South African M. macrolepidotus. A deeper body in Upper Zambezi fish compared to Incomati fish may be the biophysical reason for their lower first harmonic (ratio of body depth over SL, BD/SL $\mathrm{SZ}_{\mathrm{UZ}}, 0.2771 \pm \mathrm{SE}$ $0.0002, n=82 ; \mathrm{BD} / \mathrm{SL}_{\mathrm{IS}}, 0.2248 \pm \mathrm{SE} 0.0015, n=57$; Kramer et al., submitted for publication).

Superficially, the growling sounds of M. macrolepidotus appear to be similar to vocalisations of other mormyrid species, e.g. the growl (that sounds like snarling) or the 'croaking' grunt of $P$. adspersus (Crawford et al. 1986). However, the growls of M. macrolepidotus showed a much shorter PP, about 4-6 ms compared to about $40 \mathrm{~ms}$ in the growl, and $21 \mathrm{~ms}$ in the grunt of $P$. adspersus ('inter-click interval', see Large and Crawford 2002). The acoustic displays of M. macrolepidotus appear to be less elaborate compared to the precise and complex acoustic courtship displays of the genus Pollimyrus.

A second sound type, the tonal hoot, was also observed during agonistic behaviours in fish from all three populations. As for the growl, Incomati fish produced hoots of higher $\mathrm{H} 1$ and $\mathrm{H} 2$ frequencies than Upper Zambezi males. Therefore, the $\mathrm{H} 1$ of both sound types may be determined by the same mechanism. Hoots have already been documented for three other mormyrid species, namely P. ballayi, a

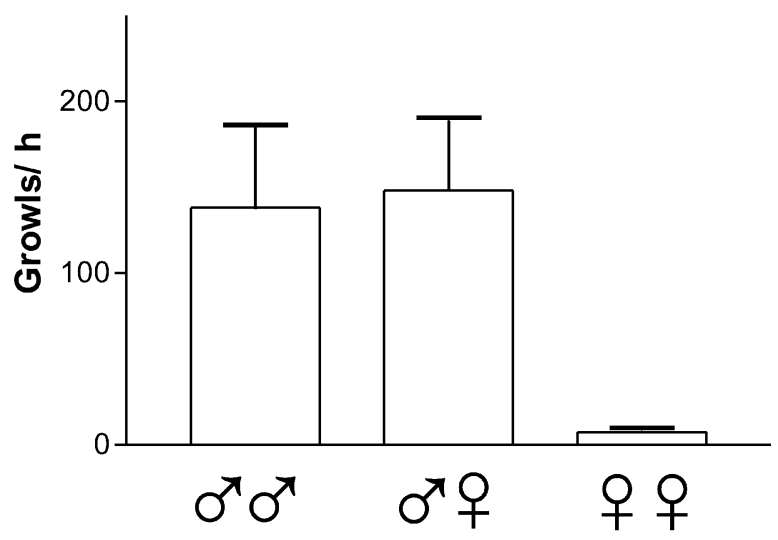

b
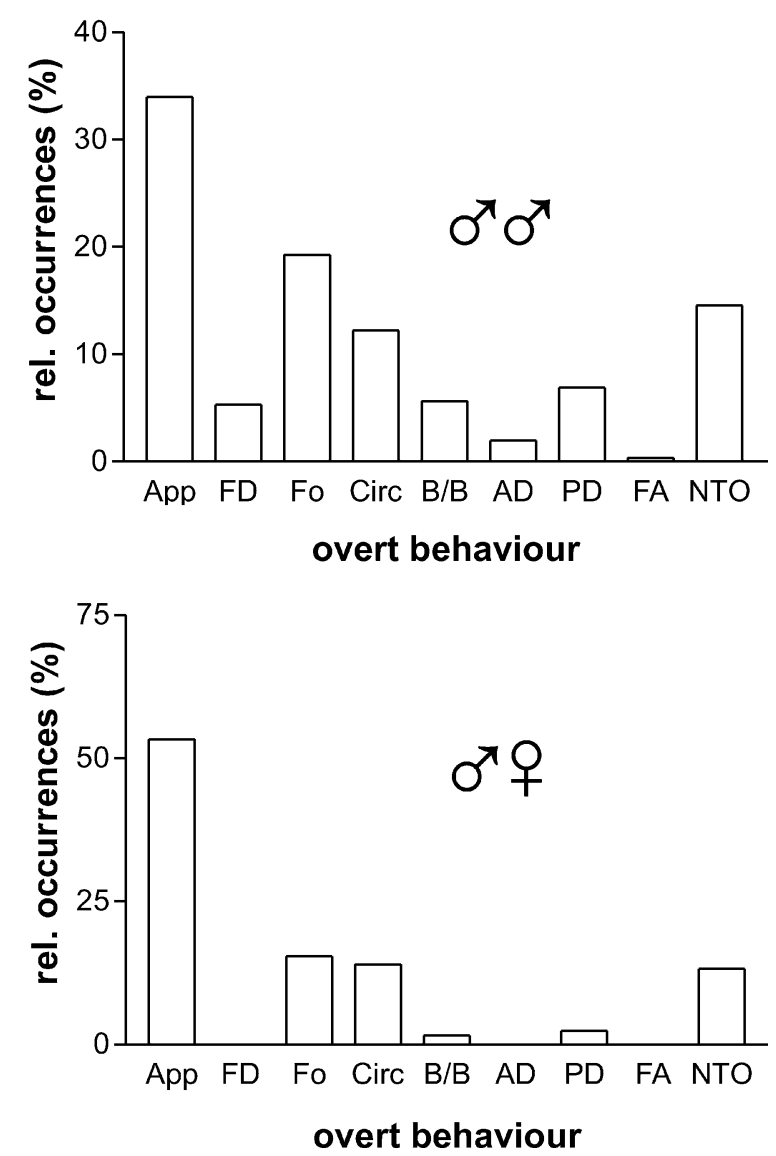

Fig. 7 Upper Zambezi fish. Motor behaviour correlated with growls.

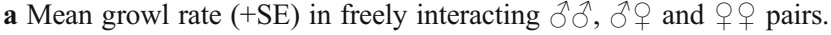
b Relative proportion of motor acts accompanying growl production.

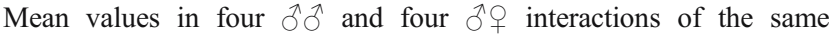
duration

P. adspersus, and P. isidori (Crawford 1997; Crawford et al. 1986, 1997a). Our observations confirm a similar ethological context, aggression or territory defense against conspecifics, also for the hoot sound of M. macrolepidotus.

The hoots of $M$. macrolepidotus resembled those of the genus Pollimyrus and Petrocephalus in structure. Hoots of $M$. 
macrolepidotus were essentially sinusoidal pressure oscillations of high intensity but of shorter duration (about $100 \mathrm{~ms}$ ) than in $P$. adspersus $(200 \mathrm{~ms})$ and of longer duration than in P. ballayi and P. isidori (about $30 \mathrm{~ms}$; Crawford et al. 1986, Crawford 1997). The peak-amplitude frequency (that was identical to H1) at about $300 \mathrm{~Hz}$ was higher in M. macrolepidotus than in P. adspersus $(200 \mathrm{~Hz})$ and $P$. ballayi $(215 \mathrm{~Hz}$ ), but similar to the hoots generated by $P$. isidori (about 346 Hz, Crawford 1997, Crawford et al. 1986, 1997a).

Why do M. macrolepidotus produce vocalisations that may be energetically costly (Crawford et al. 1997a,b; but see Amorim et al. 2002) and attract acoustically competent predators? One behavioural function of vocalisations supported by our observations is territorial defense. Thus, stable relationships with territorial neighbours may be maintained and destructive fights avoided by sound production. Some hoot characteristics of Incomati fish appeared to be correlated with a fish's size. Hoots of lowest peak-amplitude frequency and longest duration were generated by the largest male of $21 \mathrm{~cm} \mathrm{SL}$. Because the ratio of $\mathrm{CV}_{\mathrm{b}} / \mathrm{CV}_{\mathrm{w}}$ was high for all hoot characteristics of Incomati fish, hoot characteristics may function as an individual marker of quality or resource holding potential. Provided the hearing of $M$. macrolepidotus is nearly as acute as that of P. adspersus (Marvit and Crawford 2000a, b), sound characteristics might signal size during competitive interactions or the identity of territorial neighbours (see Hanika and Kramer 2005). Besides aggression, growls seem to function in mate recognition and mate choice, as suggested by a clear prespawning male-female encounter in a pair of Upper Zambezi fish that resembled the spawning posture in M. macrolepidotus (South African form, Werneyer and Kramer 2005).

Vocalisations form an integral part of the aggression and courtship behaviour of $M$. macrolepidotus, with clear differentiation between allopatric populations. Allopatric differentiation in vocalisations that accompany territorial disputes, courtship and spawning may contribute to a better understanding of the signal evolution and speciation processes in mormyrids.

Acknowledgements We thank F.H. van der Bank (Johannesburg University, Auckland Park, South Africa), Roger Bills (South African Institute of Aquatic Biodiversity, Grahamstown, South Africa) and J. Engelbrecht (Mpumalanga Parks Board) for their support in the field to B. Kramer, and in sampling of fish. We also thank Sabine Hartl for assistance with data acquisition (Buzi River fish). This work was supported by the Deutsche Forschungsgemeinschaft (DFG), grants $\mathrm{Kr} 446 / 11-3$ and $\mathrm{Kr} 446 / 11-4$.

We adhered to the 'Guidelines for the use of animals in research' as published in Animal Behaviour (1991, 41, 83-186) and the laws of Germany.

\section{References}

Amorim MCP, McCracken ML, Fine ML (2002) Metabolic costs of sound production in the oyster toadfish, Opsanus tau. Can J Zool 80:830-838

Amorim MCP, Knight ME, Stratoudakis Y, Turner GF (2004) Differences in sounds made by courting males of three closely related Lake Malawi cichlid species. J Fish Biol 65:1358-1371

Bass AH (1990) Sounds from the intertidal zone: vocalizing fish. Bioscience 40:249-258

Bass AH, McKibben JR (2003) Neural mechanisms and behaviors for acoustic communication in teleost fish. Prog Neurobiol 69:1-26

Bratton BO, Kramer B (1989) Patterns of the electric organ discharge during courtship and spawning behavior in the mormyrid Pollimyrus isidori. Behav Ecol Sociobiol 24:349-368

Crawford JD (1997) Hearing and acoustic communication in mormyrid electric fishes. Mar Freshw Behav Physiol 29:65-86

Crawford JD, Hagedorn, M, Hopkins CD (1986) Acoustic communication in an electric fish Pollimyrus isidori (Mormyridae). J Comp Physiol A 159:297-310

Crawford JD, Jacob P, Benech V (1997a) Sound production and reproductive ecology of strongly acoustic fish in Africa: Pollimyrus isidori, Mormyridae. Behaviour 134:677-725

Crawford JD, Cook AP, Heberlein AS (1997b) Bioacoustic behavior of African fishes (Mormyridae): Potential cues for species and individual recognition in Pollimyrus. J Acoust Soc Am 102 (2):1200-1212

Fine ML (1978a) Seasonal and geographical variation of the mating call of the Oyster toadfish, Opsanus tau L. Oecologia 36:45-57

Fine ML (1978b) Geographical variation in sound production evoked by brain stimulation in the oyster toadfish. Naturwissenschaften 65:493

Fletcher LB, Crawford JD (2001) Acoustic detection by soundproducing fishes (Mormyridae): The role of gas-filled tympanic bladders. J Exp Biol 204:175-183

Gray GA, Winn HE (1961) Reproductive ecology and sound production in the toadfish, Opsanus tau. Ecology 42:274-282

Graff B (1989) Firing activity of the weakly electric fish Marcusenius macrolepidotus (Mormyridae, Teleostei): logaritmic repartition of inter-pulse intervals and sequential inequality testing. Behaviour 109:258-284

Hanika S, Kramer B (2005) Intra-male variability of its communication signal in the weakly electric fish, Marcusenius macrolepidotus (South African form), and possible functions. Behaviour 142:145-166

Hopkins CD (1999) Design features for electric communication. J Exp Biol 202:1217-1228

Kramer B (1990) Electrocommunication in teleost fishes: behavior and experiments. Springer, Berlin Heidelberg New York

Kramer B (1996) Electroreception and communication in fishes (Progress in Zoology, vol. 42). Gustav Fischer, Stuttgart

Kramer B (1997) A field study of African elephantfish (Mormyridae, Teleostei): Electric organ discharges in Marcusenius macrolepidotus (Peters, 1852) and Petrocephalus catostoma (Günther, 1866) as related to sex. J Afr Zool 111:313-341

Kramer B, Van der Bank FH, Skelton PH (1998) Two new species of snoutfish (Mormyridae) from South Africa: evidence from electric organ discharges. In: African fishes and fisheries: diversity and utilisation (abstracts). Paradi Conference, Grahamstown, South Africa, $\mathrm{p} 50$

Ladich F (1990) Vocalization during agonistic behaviour in Cottus gobio L. (Cottidae): an acoustic threat display. Ethology 84:193-201 
Ladich F (1997) Agonistic behaviour and significance of sounds in vocalizing fish. Mar Freshw Behav Physiol 29:87-108

Ladich F (1998) Sound characteristics and outcome of contests in male croaking gouramis (Teleostei). Ethology 104:517-529

Ladich F, Brittinger W, Kratochvil H (1992) Significance of agonistic vocalization in the the croaking gourami (Trichopsis vittatus, Teleostei). Ethology 90:307-314

Lamml M, Kramer B (2005) Sound production in the reproductive behaviour of the weakly electric fish Pollimyrus marianne Kramer et al. 2003 (Mormyridae, Teleostei). Bioacoustics 15:51-78

Large EW, Crawford JD (2002) Auditory temporal computation: interval selectivity based on post-inhibitory rebound. J Comput Neurosci 13:125-142

Lobel PS (1998) Possible species specific courtship sounds by two sympatric cichlid fishes in Lake Malawi, Africa. Environ Biol Fisches 52:443-452

Mann DA, Lobel PS (1998) Acoustic behavior of the damselfish Dascyllus albisella: behavioral and geographic variation. Environ Biol Fisches 51:421-428

Martin P, Bateson P (1987) Measuring behaviour. An introductory guide, 1 st edn. Cambridge University Press, Cambridge, pp 48-52

Marvit P, Crawford JD (2000a) Auditory thresholds in a sound-producing electric fish (Pollimyrus): Behavioral measurements of sensitivity to tones and click trains. J Acoust Soc Am 107(4):2209-2214

Marvit P, Crawford JD (2000b) Auditory discrimination in a soundproducing electric fish (Pollimyrus): Tone frequency and clickrate difference detection. J Acoust Soc Am 108(4):1819-1825

Moller P (1976) Electric signals and schooling behavior in a weakly electric fish, Marcusenius cyprinoides L. (Mormyriformes). Science 193:697-699

Moller P (1995) Electric fishes: history and behavior. Chapman \& Hall, London, UK

Moller P, Serrier J, Bowling P (1989) Electric organ displays during social encounter in the weakly electric fish Brienomyrus niger L. (Mormyridae). Ethology 82:177-191

Myrberg AA Jr (1981) Sound communication and interception in fishes. In: Tavolga WN, Popper AN, Fay RR (eds) Hearing and sound communication in fishes. Springer, Berlin Heidelberg New York, pp 395-426

Myrberg AA Jr (1997) Underwater sound: its relevance to behavioural functions among fishes and marine mammals. Mar Freshw Behav Physiol 29:3-21
Myrberg AA Jr, Spanier E, Ha SJ (1978) Temporal patterning in acoustical communication. In: Reese E, Lighter F (eds) Contrasts in behavior. Wiley, New York, pp 138-179

Myrberg AA, Mahler M, Catala JD (1986) Sound production by males of a coral reef fish (Pomacentrus partitus): its significance to females. Anim Behav 34:913-923

Parmentier E, Lagardère JP, Vandewalle P, Fine ML (2005) Geographical variation in sound production in the anemonefish Amphiprion akallopisos. Proc R Soc Lond B 272:16971703

Rigley L, Marshall J (1973) Sound production by the elephant nose fish, Gnathonemus petersii (Pisces, Mormyridae). Copeia 1973:134-135

Scheffel A, Kramer B (1997) Electrocommunication and social behaviour in Marcusenius senegalensis (Mormyridae, Teleostei). Ethology 103:404-420

Scheffel A, Kramer B (2006) Intra- and interspecific electrocommunication among sympatric mormyrids in the Upper Zambezi River. In: Ladich F, Collins S, Moller P, Kapoor BG (eds) Communication in fishes. Science Publishers, Enfield New Hampshire, USA

Spanier E (1979) Aspects of species recognition by sound in four species of damselfishes, genus Eupomacentrus (Pisces: Pomacentridae). Z Tierpsychol 51:301-316

Stipetić E (1939) Über das Gehörorgan der Mormyriden. Z Vergl Physiol 26:740-752

Von der Emde G, Schwarz S (2002) Imaging of objects through active electrolocation in Gnathonemus petersii. J Physiol (Paris) 96:431-444

Werneyer M, Kramer B (2002) Intraspecific agonistic interactions in freely swimming mormyrid fish, Marcusenius macrolepidotus (South African form). J Ethol 20:107-121

Werneyer M, Kramer B (2005) Electric signalling and reproductive behaviour in a mormyrid fish, the bulldog Marcusenius macrolepidotus (South African form). J Ethol 23:113-125

Yan HY, Curtsinger WS (2000) The otic gasbladder as an ancillary auditory structure in a mormyrid fish. J Comp Physiol A 186:595-602

Zelick R, Mann DA, Popper AN (1999) Acoustic communication in fishes and frogs. In: Fay RR, Popper AN (eds) Comparative hearing: fish and amphibians. Springer, Berlin Heidelberg New York, pp 363-411 